\title{
O valor de uma existência: uma análise pragmática de valorizações da vida humana em situações envolvendo dinheiro
}

\author{
Camille Porto (https://orcid.org/0000-0001-6849-4033), \\ Universidade Estadual do Rio de Janeiro (Uerj), Rio de Janeiro, RJ, Brasil; \\ École des Hautes Études en Sciences Sociales (Ehess), Paris, França!.
}

Alexandre Werneck (https://orcid.org/0000-0002-7529-7633), Departamento de Sociologia e Programa de Pós-Graduação em Sociologia e Antropologia da Universidade Federal do Rio de Janeiro (UFRJ), Rio de Janeiro, RJ, Brasil".

Resumo: O objetivo deste artigo é analisar a ideia de valoração de uma existência, por meio do estudo de situações de valorização fundadas na avaliação em termos monetários. Isso é feito com a simetrização entre duas pesquisas baseadas em entrevistas em profundidade, uma sobre como pessoas em processo de egressão do sistema penal comparam o dinheiro que ganham na "vida honesta" com aquele oriundo anteriormente do crime e outra sobre como juízes calculam indenizações por danos morais relativas a mortes e perdas corporais. O diálogo entre as duas frentes permitiu observar que entra em jogo nas definições dessas situações um movimento de tornar tanto dinheiro quanto existência significativos e tornou possível depreender dois regimes de valorização da existência, um centrado no reconhecimento intrínseco da vida humana e outro concentrado na avaliação da biografia.

Palavras-chave: Existência. Dinheiro. Valoração. Avaliação. Valorização.

\section{The value of an existence: a pragmatic analysis of valuations of human life in situations related to money}

Abstract: The article aims to analyze the idea of valuing an existence by analyzing valorization situations based on evaluation in monetary terms. This is done employing the symmetrization between two studies based on in-depth interviews: one about how people in the process of egressing from the penal system compare the money they earn in "honest life" with that originally earned in crime; and one about how judges calculate compensations for moral damages related to deaths and other body losses. The dialogue between the two studies made it possible to observe that comes into play in the definitions of these situations a movement towards making both money and existence significant. It also made it possible to deduce two regimes for valorizing existence,

\author{
I. Camille Porto \\ é doutoranda \\ em sociologia no \\ Instituto de Estudos \\ Sociais e Políticos \\ da Uerj e da École \\ des Hautes Études \\ en Sciences Sociales \\ Ehess. \\ <camilleporto@ \\ outlook.com>

\section{Alexandre de Sociologia e Programa de Pós-Graduação em Sociologia e Antropologia da UFRJ. \\ <av.werneck@ifcs. ufrj.br>.} \\ Werneck é professor \\ do do Departamento
}


one centered on the intrinsic recognition of human life, and the other focused on the evaluation of one's biography.

Keywords: Existence. Money. Valuation. Evaluation. Valorization.

1. Sobre a diferença entre a condição de egresso e a de egressante, ver Camille Porto (2019:

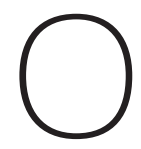
objetivo deste artigo é analisar a ideia de valoração de uma existência em situações de valorização fundadas na avaliação envolvendo o dinheiro. Isso é feito por meio do diálogo entre duas frentes empíricas distintas, mas concentradas em um equivalente universal a relacionar-se com as avaliações morais da vida humana pelos atores. A simetrização (Callon \& Latour, 1992) entre uma pesquisa sobre como pessoas em processo de egressão do sistema penitenciário (chamadas aqui de egressantes) ${ }^{1}$ comparam o dinheiro ganho na "vida honesta" com aquele oriundo anteriormente do crime e uma sobre como juízes avaliam indenizações por danos morais relativas a mortes e perdas corporais, ambas as investigações já exploradas separadamente em outros trabalhos - respectivamente, Camille Porto (2017; 2019) e Alexandre Werneck (2019b) -, permitiu colocar em contato diferentes experiências de pensar a relação entre dinheiro e existência, notadamente no âmbito moral, por meio, de um lado, de sua tradução em valores financeiros e, de outro, da efetivação (Werneck, 2012) de um ganho pecuniário, como dois regimes de valorização da existência, um centrado no reconhecimento intrínseco da vida e outro centrado na avaliação de uma biografia. Assim, foi possível problematizar mais abstratamente os fenômenos que Werneck et al. (2020) argumentam constituir a matriz da questão do valor, a valoração, a avaliação e a valorização, em momentos em que os atores são chamados a traduzir e/ou coordenar valores financeiros e valores morais.

As duas frentes, observadas em uma chave compreensiva (Weber, 1947), pragmatista (Peirce, 1992; James, 1907; Dewey, 1938) e pragmática (Boltanski \& Thévenot, 2020; Thévenot, 2006) e, consequentemente, situacionista (Thomas, 1969, Cicourel, 1964), que têm marcado os nossos trabalhos em separado (Werneck, 2012; 2014; 2015; 2020; Porto, 2017; 2019), permitiram melhor entender aquilo que chamamos de disputas de valor - quando os atores são chamados a controvérsias sobre os termos da atribuição de valores - nas situações em que entram em jogo objetos de valor intangíveis e/ou associados a domínios por eles considerados como apartados da vida econômica, ou propriamente humanos (Abercrombie, 2020), aqueles, como mostram em outro trabalho um de nós e uma colega (Werneck et al., 2020) e, reiteraremos aqui, marcados pela singularidade absoluta. Nos dois casos, observamos entrar em cena a busca por um caráter significativo nas definições de situação (Thomas, 1969): por um lado, egressantes, ao revisitarem suas histórias a partir de um ponto fixo no presente - fase híbrida, estabelecida 
fora dos limites físicos da prisão, mas ainda inserida no sistema penitenciário -, qualificam este seu momento e o anterior - e os selves (James, 1950; Cooley, 1902; Mead, 1934) a eles correspondentes ${ }^{2}$ - a partir dos montantes financeiros obtidos, de onde o dinheiro vem, da "facilidade" ou dificuldade de obtê-lo e/ou a que ele se destina, demonstrando uma busca por uma qualificação dessas relações com o ganho $^{3}$ como significativas; por outro lado, juízes, ao avaliarem o quanto se deve pagar como compensação pelos chamados danos morais (Sanseverino, 2010; Bittar, 2015), enfrentam o desafio de um duplo ajustamento entre a razoabilidade do valor financeiro vis-à-vis outros casos (e princípios legais), e entre esse mesmo valor e a busca pelas especificidades do caso particular, tornando a compensação também significativa para os envolvidos.

Vejamos, então, duas situações de avaliação representativas de nossos campos ${ }^{4}$ :

Enquanto o dinheiro do crime evaporou [...] de uma forma tão mágica, a mixaria que recebo do trabalho rende pra caramba. Um carro que eu conseguia numa noite, agora eu estou pagando em um ano. Hoje foi um dia [de trabalho] muito bom, tá? Então, vamos contar comigo aqui [saca a carteira e começa a contar dinheiro], vamos lá: $\mathrm{R} \$ 100, \mathrm{R} \$ 200, \mathrm{R} \$ 300, \mathrm{R} \$ 400$. Eu fico feliz de pegar essa mixaria aqui e pagar a prestação do meu carro. Eu fico feliz de comprar pro meu filho a moto que ele queria, sabe? É gostoso, esse dinheiro aqui rende pra caramba. Sendo que com R\$30 pra $\mathrm{R} \$ 40$ mil eu voltava duro de sexta pra segunda-feira, sabe? Sem dinheiro nenhum, nenhum, durinho. Aí eu tinha que roubar de novo. Isso aqui não, isso aqui eu pago a faculdade do meu filho, eu pago... É difícil, não sobra nada, mas é gratificante, sabe?

Em caso semelhante - de morte de feto por atendimento inadequado - o STJ [Superior Tribunal de Justiça] fixou a compensação por dano moral em R\$ 150 mil [...]. Nesse aspecto, [é] importante salientar que o médico que assistiu a autora durante o pré-natal atuou dentro da boa prática médica, como destacado pelo perito [...], e que o dever de compensação ora reconhecido visa punir a falta de integração entre os médicos das rés no que atine a resultados de exames realizados, e não a um erro que tenha sido cometido pelo médico assistente, razão pela qual se reduz a compensação para $R \$ 100$ mil, devendo ainda incidir sobre tal valor o percentual de $56,26 \%$, que corresponde à probabilidade de o feto nascer com vida em um parto prematuro. Por conseguinte, o valor da compensação fica fixado em $\mathrm{R} \$ 56.260,00$ a ser dividido entre os autores.

O primeiro trecho mostra uma comparação promovida por um "beneficiário" 5 de livramento condicional, em uma entrevista em 2016, entre o salário de seu trabaIho atual e os ganhos anteriores no crime. No usufruto dos chamados "benefícios
481).

2. Conforme a

citada bibliografia

a respeito, o self

é uma unidade de

individuação sígnica

formada por outras

unidades sígnicas (o

eu - sua dimensão

mais íntima e

constante, referente

aos comportamentos assumidos e criados

pelo indivíduo

diante de reações

sociais formalizadas

- e o mim - a

mais variante, já

que concerne à

reprodução das

reações socialmente

construídas e

às perspectivas

aprendidas sobre

si mesmo com os

outros significativos,

o que ocorre em

conformidade com

as mais diversas

situações nas quais

os indivíduos se

encontram no

decorrer de suas

trajetórias). Partindo

dessa premissa,

tomamos os

diferentes momentos

e contextos da vida

dos atores como

configurações

produtoras, muitas

vezes, de selves

distintos.

3. Como

procedimento

metodológico/

epistemológico,

a simetrização

ultrapassa os limites

da mera comparação,

já que tem como

objetivo, segundo

Callon e Latour

(1992: 348), "não

alternar entre um realismo naturalista e um realismo social, mas [...] descrever natureza e sociedade [ou quaisquer pares originalmente 
distintos como universos refratários um ao outro] como resultados gêmeos de uma terceira atividade, [...] a construção de redes". Trata-se aqui de tomar os dois mundos empíricos com o mesmo ferramental analítico, a fim de compreender a fenomenologia subjacente (isto é, o enredamento de elementos, ainda segundo os autores) a ambos em termos da tríade valorativa aqui estudada.

4. A fim de preservar as identidades de todos os envolvidos, nos trechos de processos judiciais e entrevistas, de juízes ou egressantes, os agentes não serão identificados e terão evitadas quaisquer alusões identificadoras - sendo usados inclusive os gêneros genéricos próprios a cada substantivo.

\section{5. É assim que} egressantes costumam ser designados em documentos oficiais da Secretaria de Estado de Administração Penitenciária do Rio de Janeiro (Seap/RJ), que os qualificam nos termos de seus benefícios penais e os conduzem ao processo de egressão do sistema. penais", o apenado, tornado, assim, egressante, tem sua pena restritiva de liberdade convertida em pena restritiva de outros direitos, cujo cumprimento ocorre no interior da sociedade mais ampla, após o cumprimento de regime fechado (Porto, 2019: 494). Os benefícios são concedidos pela Vara de Execuções Penais (VEP), do Poder Judiciário do Estado do Rio de Janeiro (PJERJ), e fiscalizados pelo Patronato Magarinos Torres, órgão da Secretaria de Estado de Administração Penitenciária do Rio de Janeiro (Seap/RJ). Nessa condição, os atores precisam, entre outras obrigações, se apresentar regularmente ao Patronato para assinar prontuários, comprovar empregabilidade e se submeter a atendimentos técnicos dos departamentos de Psicologia, Serviço Social e Terapia Ocupacional. Como mostram vários trabalhos (Zaluar, 1985; 2004; 2005; Misse, 1999; Grillo, 2013; Teixeira, 2013; Feltran, 2014) e a fala do entrevistado, o crime pode render ganhos de grande monta que rivalizam simbolicamente com os do "trabalhador" (Machado da Silva \& Leite, 2008).

O segundo trecho, por sua vez, advém de uma sentença sobre danos morais, proferida pela primeira instância da Justiça Fluminense em 2017. De acordo com a definição do próprio direito, os danos morais são aqueles "relativos a elementos [do] complexo valorativo intrínseco [do indivíduo], nas projeções da sociedade" ou "relativos a atributos valorativos, ou virtudes, da pessoa como ente social, ou seja, integrada à sociedade, [...], dos elementos que a individualizam como um ser" (Bittar, 2015: 34-35). Dessa maneira, o sentido do termo "moral" nessas causas explicita sua dimensão interpretativa, apontando para seu caráter abstrato e subjetivista: seria moral aquilo que demanda esforço para ser objetivado porque pertence ao domínio interpretativo. Trata-se da causa em que, diferentemente dos danos patrimoniais ou dos danos pessoais, ambos de tangibilidade objetiva (como a perda de um bem ou um prejuízo pessoal de valores financeiros definidos), se avalia a compensação por uma perda em um plano puramente abstrato. No caso em questão, a questão é se se compensa os pais pela dor da perda de seu bebê, natimorto por suposto erro médico - algo além, portanto, de compensá-los como consumidores por um mau atendimento na prestação de um serviço.

No primeiro caso, vê-se uma reinterpretação de dados quantitativos qualitativamente: poucas centenas de reais para uma família por um mês "rendem mais" do que $\mathrm{R} \$ 30$ mil ou R\$ 40 mil para um único indivíduo em um fim de semana. É uma experiência de comparação radical a seu próprio respeito e a respeito especialmente daquilo com que se gasta o dinheiro: enquanto os ganhos agigantados oriundos da ocupação como ladrão de carga eram usualmente direcionados a prazeres imediatos - ele diz que "gastava com bebidas, mulheres, viagens, curtição", o que levava o entrevistado a voltar para casa "de sexta pra segunda-feira, sem dinheiro nenhum, nenhum, durinho" -, os ganhos modestos do trabalho como motorista de 
van são direcionados ao sustento de sua família, a bens duráveis e ao futuro - dessa monta, como destaca, "não sobra nada", mas "essa mixaria", diferentemente da renda anterior, "é gratificante".

No caso dos danos morais, por outro lado, o magistrado decidiu acolher a demanda do casal, reconhecendo, assim, que a perda da vida do filho merecia a resposta chamada pela Justiça de "reparação integral" (Sanseverino, 2010) ${ }^{6}$. O que chama atenção no trecho, entretanto, é a forma de quantificar o valor, baseada em uma espécie de fator de correção: como um especialista havia indicado um percentual de probabilidade de sobrevivência de um bebê prematuro, o juiz conclui que em vez do que deveria ser pago como compensação por um bebê nascido no tempo normal - e que corresponderia a $100 \%$ da indenização -, deveria ser paga uma proporção desse total, que o minora praticamente à metade. A decisão, após recurso, foi reformada na segunda instância, reconhecendo-se o direito à íntegra do valor e não a uma proporção baseada em uma atenuação (justificada, naquele caso específico) pela hipertensão materna: em vez do valor original único para o casal, o desembargador determinou o pagamento de $\mathrm{R} \$ 100$ mil para cada um dos pais.

Assim, trata-se, no primeiro caso, de se julgar se um dinheiro ganho é bom ou não. No segundo, a questão é julgar se é bom ou não que um dinheiro seja ganho.

A pesquisa sobre os egressantes penais consistiu em uma análise sobre a "carreira moral" (Goffman, 1974) de pessoas que se encontram em processo de egressão do sistema penitenciário fluminense (Porto, 2017; 2019) por meio de 25 entrevistas semiestruturadas no interior do Patronato Magarinos Torres e nas quais os egressantes foram convidados a refletir sobre suas trajetórias. A pesquisa sobre os danos morais, por sua vez, analisou o desafio fundamental da Justiça para ser justa quando se opera um modo de justeza não inscrito na objetividade. Para tanto, foram realizadas 16 entrevistas semiestruturadas com magistrados, entre juízes de primeira instância, desembargadores e um ministro do STJ, ao mesmo tempo que se analisaram 32 ações de danos morais ${ }^{7}$. O objetivo era refletir sobre como os julgadores objetivam em valores monetários danos morais, como a perda de uma vida ou outros elementos intangíveis (Werneck, 2019b).

Os dois casos apresentados, como os outros analisados, expressam uma tensão entre esferas por vezes representadas como imiscíveis, a da economia e a do propriamente humano. Trata-se de uma representação apontada por Viviana Zelizer (2011) como a construção de mundos hostis (em seu tratamento, o econômico e o da intimidade) e por Nicholas Abercrombie (2020) como distintos regimes de valor (opondo o dinheiro e o sagrado). Os exemplos expressam uma disjunção que salta
6. Doutrina segundo a qual se alguém é vítima de um dano deve buscar a reparação mais ampla possível, em todas as dimensões, até mesmo em termos morais.

7. A estratégia adotada para se entrevistar os julgadores consistiu em seguir os processos judiciais: a partir da amostra de ações por danos morais, buscou-se falar com os magistrados envolvidos e seguir uma bola de neve de cada caso. Mas nem todo julgador pôde ser acessado ou concordou em falar. 
aos olhos, já que tanto a tentativa de atribuir pouco valor a muito dinheiro e muito valor a pouco dinheiro soaria para certo olhar como um moralismo irracional por parte daquele que qualifica esses montantes não em termos de poder monetário e/ou aquisitivo, mas de satisfação ("é gratificante") - um relativismo tão imerso no cotidiano da vida econômica quanto dizer que um automóvel é barato enquanto um doce é caro (Weber, 2002; Neiburg, 2010) -, quanto a tentativa de critério para a objetivação do valor da perda da vida de um filho soa como mecanização que sequestra sua humanidade e sua singularidade (Karpik, 2010) - o que é expresso no recurso amparado pela segunda instância com a afirmação de que "[a] falha dos [r]éus retirou não 56,26\% de chance de vida [do filho] dos autores - como afirma a sentença -, mas $\operatorname{sim} 100 \%$, porque a este não foi dada sequer a chance de nascer para sobreviver". Essa disjunção entre domínios nos apareceu na análise como uma composição complexa entre aquilo que, em outro trabalho, um de nós e uma colega (Werneck et al., 2020) chamaram de hostilizações, oposições/críticas situadas à economia, e um quadro de indefinição da situação (Werneck, 2019a; 2020) que permite aos atores fazerem conviver em um mesmo processo de avaliação o mundo de singularidades próprio aos "valores morais" (expressos por meio da interpretação) e o mundo de diferenciações próprio aos "valores objetivos" (ajustados a e lastreados em elementos objetivos do mundo).

\section{O valor como questão sociológica e os três fenômenos valorativos relevantes}

O problema analítico fundamental aqui em jogo tem a ver com a análise do papel desempenhado pelo valor em um tipo específico do que William I. Thomas (1969: 42) chamou de definição da situação, "um estágio de exame e deliberação [...] preliminar a qualquer ato comportamental autodeterminado" e que diz o que está acontecendo ali, permitindo aos humanos tratarem as situações como "reais em suas consequências" (Thomas \& Thomas, 1938: 572). Ao adotar essa partida situacionista, concentramo-nos nas situações em que o dinheiro possa comparecer como elemento para efetivar o valor de um humano, situações cuja definição implica avaliar uma existência e agir a partir dessa avaliação.

O empreendimento de uma pesquisa sobre o que chamamos de conflitos de valoração (Werneck et al., 2020), no âmbito do "estudo dos valores e das valorações" (Cefaï et al. 2015), nos fez mergulhar na reflexão sobre o conceito de valor, que vai dos clássicos, como Georg Simmel (2011) ou Karl Marx (Ash, 1965), a tratamentos contemporâneos (Kluckhohn, 1951; Baier, 1973; Heilbroner, 1983; Graeber, 2001; Rezsohazy, 2006; Pedersen, 2008; De Lastic, 2014; Brosch \& Sander, 2016; Heinich, 
2017). Das múltiplas abordagens analisadas, concentramo-nos na ideia de sociologia axiológica (Heinich, 2017: 140): o valor é um atributo associável a "coisas, pessoas, ações e estados do mundo". Mas, para adotá-la, nos municiamos de um tratamento clássico: partimos do tratamento de Max Weber (1947), segundo o qual o valor é uma camada do sentido, chave de sua sociologia da ação, compondo uma espécie de, como mostra Werneck (2019a: 7 e 9), semiótica social. Nessa chave, o termo valor passa a expressar um tipo peculiar de significado, aquele que, construído como grandeza (Boltanski \& Thévenot, 2020; Heinich, 2017), sendo passível de medição e comparação, expressa a importância atribuída a algo, na forma da quantidade dessa grandeza - e essa importância se torna a forma privilegiada do sentido efetivador de algo.

Trata-se, dessa maneira, de um nome do bem, uma de suas formas, preenchendo coisas com quantidades desse bem e permitindo compará-las. Assim, em um modelo compreensivo, os atores são chamados a legitimar, efetivar (Werneck, 2012; 2021) uma ação (aqui, uma situação) - e, por extensão de sentido, tudo que the sirva de metonímia (como dissemos a partir de Nathalie Heinich, "coisas, pessoas, ações e estados do mundo"), por meio da demonstração de seu preenchimento com uma dessas formas do bem, com valores. Pode ser honra, pode ser beleza, pode ser justiça, podem ser $\mathrm{R} \$ 400$ ou $\mathrm{R} \$ 40$ mil, pode ser seu caráter significativo - qualquer designativo que permita dizer que algo tem mais ou menos dele do que outro algo, atribuindo-Ihe importâncias comparativas.

Heinich (2017) qualifica ainda três sentidos do termo valor: como grandeza (caso em que o fenômeno em jogo é a expressão do quanto algo vale); como objeto (em que a questão é a designação de algo como valioso); e como princípio (segundo o qual o horizonte é o da designação do princípio, do valor segundo o qual se avalia), de modo que em seu tratamento os três fenômenos relevantes são, em seus termos: o atrelamento, a medição e o julgamento. Em nossa interpretação, propomos Werneck et al., 2020) outra tipologia, centrada nos processos efetivos de operação do valor:

i. valoração: a qualificação interpretativa de coisas segundo quadros valorativos (isto é, a escolha do critério de interpelação da efetividade de algo - ou seja, apontando em que termos algo é o bem, é bom);

ii. avaliação: a ponderação da magnitude do peso de algo segundo um valor (isto é, a medida do quanto algo A vale em termos de valor B) e a comparação ponderada entre diferentes coisas segundo esse mesmo critério (isto é, a definição de que coisa, C ou D, apresenta mais do valor $\mathrm{B}$, sendo mais valiosa que a outra segundo esse parâmetro); 
iii. valorização: a ampliação e/ou o reconhecimento do valor de algo segundo o critério eleito na valoração (isto é, o quanto E pode passar a ser mais valioso, tendo isso sido notado ou não, tendo acrescentado a si mais de valor $\mathrm{B})$.

\section{A existência como forma de efetivar a vida humana e seu valor}

8. Sobre a relativização desse quadro, ver Jussara Freire (2010) e Jussara Freire e César Pinheiro Teixeira (2016).
A análise mostrou uma passagem entre dois estados de qualificação nas situações de valoração da vida humana (tomada em sua natureza biológica), o de humano e o de uma existência. A distinção entre os dois estados se encontra na transição entre uma indistinção produzida por um estado de crença (Peirce, 1992) a respeito do estatuto de pertencimento à humanidade comum ${ }^{8}$ (isto é, de uma ideia de "humano" em sua dimensão político-social, o que confere a ele lugar de dignidade) e a entrada em jogo de uma reflexão a respeito do lugar desse humano na existência (Boltanski \& Thévenot, 2020), uma reflexividade sobre si e os outros a partir do reconhecimento de sua finitude e de seus afetos e sofrimentos (Williams, 1982), cujo processo está intimamente relacionado ao de constituição de selves (James, 1950; Mead, 1934), como "uma existência", portanto. É no quadro desse exame de estatuto que se pode falar de uma existência (um humano problematizado em suas afecções com o mundo). As pesquisas mostraram, por meio de dois tipos de avaliação que colocam sobre a mesa notadamente as finitudes e os valores existenciais das pessoas, que esse movimento corresponde a um primeiro passo do processo aqui em jogo, o de valoração desse humano: é por meio da eleição de quadros de valor pertinentes para qualificar esse humano que ele se implica no quadro da existência. Foi possível, então, discernir duas principais formas de conferir sentido a essas existências, dois regimes, implicando duas formas de qualificação: uma centrada no humano como portador de uma biografia (isto é, de uma história singular que efetiva a existência como boa, determinando um reconhecimento meritório ou pelo menos congruente com essa história); outra, concentrada no humano como unidade intrínseca e por isso digna de reconhecimento - no sentido de Georg W. F. Hegel (Honneth, 2009) - de humanidade equânime e equivalente com os outros (Boltanski \& Thévenot, 2020), mas ao mesmo tempo singular absoluta (Werneck, 2012) em sua existência mesma. Em um primeiro plano, a pesquisa com os egressantes mostrou fortemente como a biografia pode ser mobilizada para dar sentido a um humano como existência: é por meio de uma narrativa biográfica de oposição entre o self pré-cárcere e o pós-cárcere que os egressantes atribuem valor não só a diferentes momentos da vida, mas principalmente a eles próprios como pessoas. Por sua vez, a pesquisa com as indenizações deixou claro o papel do reconhecimento (de direito e dignidade) como núcleo dessa mesma humanidade valorada (existência). 
Mas se a operação de oferta de sentido é suficiente para qualificar uma vida como existência, foi possível ver que a qualificação moral desta muito se beneficia do comparecimento de objetos que possam Ihe servir como índices (Peirce, 1977): em vez de se promover uma passagem automática da existência à boa existência (aquela que, sendo finita, conta), torna-se necessário um processo de comprovação (Boltanski \& Thévenot, 2020): é necessária a indiciação da positividade dessa existência, ou seja, de tratamento desse objeto como um tipo de signo capaz de indicar o caráter existencializado da vida. Trata-se, nesse sentido, da valorização dessa existência, do processo de explicitação (e de ampliação aos olhos dos avaliadores) da grandeza, do valor das existências vis-à-vis os critérios estabelecidos na valoração.

E foi nesse ponto que o dinheiro se mostrou um dispositivo digno de nota: esse equivalente universal, notadamente porque expressa a livre agência dos humanos (Simmel, 2011; Bloch \& Parry, 1989), se ofereceu nas duas pesquisas como o índice capaz de sustentar a qualificação de boa existência ao se colocar como metonímia tanto para a biografia como para o reconhecimento. Esse processo de indiciação, correspondendo a um processo de avaliação, busca ponderar por meio de valores financeiros (quantificados, portanto) e por sua qualificação moral o valor daquela existência. Assim, se no caso do criminoso o que efetiva a boa existência é uma equivalência entre dinheiro e sua condição por meio do montante desmedido e continuamente acessível, disponível (o que explicita sua capacidade de agenciamento), no do egressante é na origem, o "trabalho honesto", no destino, o sustento, e na afirmação de sua liberdade que se traduz a relação entre dinheiro e existência positiva ${ }^{9}$. Ao mesmo tempo, no caso das indenizações, será o montante (grandeza) justamente atribuído, razoável e ponderado o responsável por transacionar, em uma primeira camada, boa existência e reconhecimento. Esses dois diferentes regimes de valorização da existência por meio da avaliação em termos de um equivalente, um regime de biografia e um regime de reconhecimento, permitiram qualificar, então, gramáticas da efetivação da boa existência nas quais o dinheiro comparece como elemento ao mesmo tempo efetivador e a ser efetivado, em um processo mútuo de valorização: ele faz as existências valerem ao mesmo tempo que extrai de suas formas práticas (a história de vida e a ponderação da vida em si) sua efetividade para agenciar as participações desses atores, cuja existência está em avaliação nas situações em que as comparem como tais.

O argumento pode ser sintetizado pelo seguinte esquema:
9. Isso também permitiu observar as desvalorizações cruzadas, segundo as quais o trabalhador desqualifica a existência de seu passado/ self criminoso justamente pela relativa facilidade de acesso e pela abundância e o mesmo por parte do criminoso, que desqualifica a alternativa de viração baseada no trabalho lícito por meio da origem "otária" do dinheiro e seu destino "careta". 




Elaboração própria

No caso dos egressantes Porto (2017; 2019), havia já demonstrado que a experiência de encarceramento produz uma sequência regular de mudanças nas máquinas valorativas dos atores a respeito de si e do mundo. Trata-se, em outras palavras, de uma transformação na parcela da cognição que analisa o que é importante e como isso ocorre, influenciando suas operações de valoração, avaliação e valorização. Para a autora (2017; 2019), a nova chave avaliativa de egressantes penais se estabelece nos termos do que ela chama de ressaca, um sintoma da incorporação da experiência de prisão, que revela o anseio de "nunca mais voltar para aquele lugar", e, no limite, de se afastar permanentemente do crime. Mas, embora essa ressaca se manifeste em todos os casos, a parcela desses atores de interesse aqui é aquela que se engajou, em sua vida pregressa ao cárcere, no universo de ação e significação representado como o "mundo do crime" (Ramalho, 1979; Zaluar, 1985; Machado da Silva, 1993; Misse, 1999; Barbosa, 2006; Feltran, 2008; Hirata, 2010; Lyra, 2013; Grillo, 2013; Teixeira, 2013) - diferentemente de outros, que praticaram apenas um delito e/ou não se engajaram em uma carreia criminosa. E apesar de a inserção no mundo do trabalho formal ser uma exigência institucional para comprovação de reeducação pós-prisional, esse movimento é representado por eles como índice de seu comprometimento com a vontade de "mudar de vida" e permanecer "no lado certo".

O tratamento em termos de definições de selves nos dois momentos da carreira moral observados no estudo dos egressantes permitiu tratar uma mesma pessoa 
efetivamente como dois personagens distintos, uma vez que, dada a transformação no "esquema de imagens [da pessoa] para julgar a si mesma e aos outros" (Goffman, 1974: 128) determinada pela carreira, tem lugar dois regimes completamente distintos de tratar o valor de si por meio do dinheiro e o valor do dinheiro por meio de si. Ao mesmo tempo, a definição de um self vítima e de um self indenizando da parte da Justiça buscam direcionar a forma de avaliação por um ajustamento entre figuras típicas e valores congruentes (a vítima é aquele self que, definido, merece ter sua perda compensada e o indenizando aquele que, injustiçado, merece a justa compensação) $)^{10}$.

De fato, as transformações produzidas na carreira moral de egressantes influenciam seus modos de moralizar e se relacionar com o dinheiro e seu uso no decorrer de suas trajetórias, o que é demonstrado por suas falas sobre os períodos precedente e posterior ao cárcere. Por sua vez, as entrevistas com os magistrados diante dos processos mostraram, como dito, um investigativo movimento pendular entre ajustamento à normalidade e avaliação moral em termos de singularidade. Assim, tomamos o dinheiro como entidade moral carregada de ideias, crenças e valores não concedidos a priori e sim dependentes de serem construídos e efetivados em seu empreendimento (Wilkis, 2013).

Os magistrados citam a mobilização de um imperativo mais ou menos estabelecido no Brasil, em torno do chamado método "binário" ou "bifásico" (Sanseverino, 2010), fundado em uma avaliação em duas etapas: em uma primeira, faz-se um levantamento de outros resultados indenizatórios praticados em casos semelhantes, para, deles, se buscar um valor típico e o justo por referência a este, objetivando-se o montante por seu caráter habitual, conferindo-Ihe razoabilidade ${ }^{11}$; em uma segunda fase, busca-se observar a causa específica para, em suas particularidades, medir-se o quão ela esteja aquém ou além do tipo ideal prospectado na primeira fase, e, com isso, se ajustar o valor a partir desse cotejamento. As entrevistas revelaram que esse segundo movimento, em vez de representar uma nova rodada de ajustamento objetivo, pelo comparecimento de especificidades que permitiriam comparar (diferenciar) objetivamente os casos (como em uma precificação), implica, antes, um movimento investigativo (Dewey, 1938) de busca por elementos de singularidade, a fim de tornar a indenização significativa. O objetivo seria ultrapassar uma disputa valorativa: eles relatam deparar-se com algo que poderíamos chamar de excesso de justeza na avaliação, uma "dureza" de estabelecimento por demais ajustado à normalidade, porque muitas vezes os valores pecuniários parecem ainda soar ruidosos aos ouvidos da ideia de justiça e de compensação de um sofrimento, como percebem ao avaliar o caso. Como diz um desembargador:
10. Evidentemente, em vários processos a vítima e o indenizando são a mesma pessoa.

11. Alguns magistrados, entretanto, preferiram se referir ao "bom senso" como princípio norteador dessa avaliação. Além disso, há da parte de juízes mais progressistas a tendência a indenizações segundo outras metodologias, mas que igualmente mostram uma digamos - vontade de significância. A análise desses outros modelos, menos recorrentes, entretanto, ultrapassaria os limites deste artigo. 
Não se trata de apreçar o montante da dor, o que é incomensurável, mas, de alguma forma, dar àquela pessoa um lenitivo qualquer, e aí na forma de um valor de dinheiro, que pudesse de alguma forma, de alguma forma, compensá-la. Mas, em alguns momentos, alguém no plenário simplesmente encontra um problema: "Espere aí! Esse valor não está certo!" Como ele sabe? Ele não vê como aquele valor possa importar para os envolvidos.

Os magistrados, assim, expressaram muitas vezes que sua tarefa de justiça está sempre incompleta no caso dos danos morais, já que seria impossível compensar "verdadeiramente" uma perda tão grande quanto a de um ente querido, de uma carreira, de uma reputação. Para dar conta disso é que parece surgir o mecanismo da singularização, da indenização com o valor significativo. Nesse sentido, esse valor adquire um caráter semiótico mais complexo, porque se projeta que ele tenha algo a dizer.

Uma nota sobre o dispositivo analítico de simetrização aqui utilizado: as pesquisas nos colocaram, como entrevistadores, diante de atores que, analiticamente traduzidos em um sistema actancial, isto é, como actantes (Greimas, 1976; Latour, 1997), tratamos como avaliadores. Eles promovem as operações de valoração, avaliação e valorização de um ser objeto de sofrimento existencial e, portanto, promovem uma operação de reflexão (avaliativa) sobre esse sofrimento. Ora, essa reflexão se dá, na pesquisa, incontornavelmente em três possíveis dimensões, uma prática, uma analítica e uma prático-analítica. Na primeira, os atores "refletem sem refletir", isto é, colocam em ação sua capacidade moral e ponderam, sem sequer pensar nisso reflexivamente e/ou tomar consciência disso (é o refletir para fazer, quando se pondera, por exemplo); na segunda, pensam no que estão fazendo como atividade controlada pela consciência (é o refletir para pensar no que se faz/fez, como na entrevista); na terceira, fazem esta mesma operação, mas no âmbito de uma ritualística da reflexão, em que são levados a expressar em termos comunicáveis a própria operação reflexiva (por exemplo, no relatório do processo judicial, no qual o magistrado justifica seu julgamento, o que é reflexivo, mas conformado pelos elementos linguageiros e operacionais da burocracia e da lógica do direito ou, no caso dos egressantes, nas narrativas sobre o que tiveram que dizer para o Estado ou para os familiares sobre sua condição anterior). Ora, nas entrevistas, os pesquisados são estimulados pelo pesquisador a revisitar essas operações, produzindo-se uma camada reflexiva a mais sobre todas elas. Como este é um estudo sobre representações dos atores sobre suas práticas avaliativas, consubstanciadas pelos accounts (Scott \& Lyman, 2008) por eles oferecidos ao pesquisador e/ou a terceiros (na terceira dimensão), as circunstâncias específicas dessas operações se tornam elementos internos de suas reflexões e não dados ecológicos objetiváveis, estando 
a simetrização concentrada nos pontos em comum relativos à operação reflexiva/ avaliativa.

Nesse sentido, é digno de nota que estejamos diante de movimentos de diferentes naturezas em cada um dos campos e que se equalizem no plano analíticos porque se equalizam no plano reflexivo: os juízes avaliam as existências de outras pessoas (vítimas primárias e secundárias/indenizandos) enquanto os egressantes avaliam a si mesmos. Mas a simetrização se torna possível a partir do momento em que o que está em jogo é justamente uma operação reflexiva. Ora, em uma "carreira moral" (Goffman, 1974; Porto, 2019), o self é transformado em sua parcela avaliativa, mas continua sendo o mesmo self, uma vez que, por estatuto, este não apenas é sempre cambiante como é entendido como integrando um continuum. Enunciados comuns, como: "Eu era criança, hoje sou adulto" ou "Eu era assim ou assado e não sou mais", são frases sobre si que estabelecem ao mesmo tempo a compreensão de um continuum ("Eu") e um distanciamento que representa uma operação analítica da parte do próprio pesquisado (ao mesmo tempo em que é construída como tal pelo pesquisador): ele se separa de si para falar de si - é o self de hoje falando do self de ontem, tornando-o "mim" em uma operação de espelhamento. Por sua vez, os magistrados olham para os sofrimentos de vítimas "diretas" e "indiretas" expressões usadas na vitimologia para distinguir aqueles que objetivamente foram afetados pelo evento-chave e aqueles que sofreram suas consequências indiretamente (como, respectivamente, o bebê e os pais no primeiro caso apresentado), mas que evidentemente representam posições passíveis de ser ocupadas pela mesma pessoa (como, em outro processo, um homem ferido e preso ao ser confundido com um criminoso e indenizado por danos morais) - e esses magistrados fazem isso sem precisar pensar "em si" diretamente. Ora, como aquela operação de reflexão dos egressantes é feita por distanciamento (construído abstratamente, o que pressupõe um trabalho social semelhante ao de se tornar juiz), na prática as operações dos avaliadores aqui observados se equalizam. O importante é que, do ponto de vista do quadro aqui esboçado para dar conta de avaliações da vida humana existencializada, as valorizações são resultado de uma complexa operação de distanciamentos e aproximações operadas no curso das definições de situação aqui observadas.

\section{O dinheiro "fácil", o "enriquecimento ilícito"}

Uma primeira face da participação do dinheiro na valorização de uma existência advém de uma hostilização do dinheiro considerado indevido, injusto ou imerecido, seja no que diz respeito a seu recebimento, seja relativamente ao montante. Nos 
dois campos, observa-se a mobilização de uma crítica a qualquer grandeza mercantil obtida sem a observação de uma fórmula de investimento adequada (Boltanski \& Thévenot, 2020). Assim, o econômico é hostilizado na medida em que se torna um índice de valor injusto: entra em jogo uma dicotomia moral, segundo a qual o dinheiro ganho é avaliado como bem de si reprovável por não representar um bem comum (Boltanski \& Thévenot, 2020; Werneck, 2012). Assim, vemos, de um lado, o dinheiro ganho na vida pregressa do crime ser hostilizado pelos egressantes como "fácil" e aquele pago como indenização a certas causas de danos morais ser descrito por juízes como "enriquecimento ilícito".

Os egressantes descrevem o mundo do crime como uma entidade sedutora, cujas propriedades comprometeriam o discernimento e os sentidos, sobretudo a visão, produzindo uma espécie de cegueira orientada pelos ganhos dessa vida e ofuscando os prejuízos, custos e riscos. Assim, eles atribuem a essa forma de vida um caráter ilusório, construído no contato com amigos, status, poder, excitação e, sobretudo, dinheiro. Essa ilusão consistiria em uma representação construída em um momento de "desilusão", de "desencanto", de "clareza", em que seria possível, enfim, enxergar. Para eles, o principal motivo de engajamento no mundo do crime é o expressivo ganho monetário em curtíssimos períodos se comparado ao modelo das atividades lícitas. Como conta um: "Eu fiquei nessa porque era tão fácil, tanto dinheiro guardado, vou trabalhar pra quê? Mas tudo mais fácil uma hora dá ruim, não tem jeito". De fato, a relativa facilidade descrita se refere a uma posse exponencial - e incoerente com o tempo investido - apresentada a eles como certa e previsível. Por isso, o dinheiro "fácil" é tomado como aquilo que Luc Boltanski e Laurent Thévenot (2020) chamam de "graça", uma grandeza caracterizada, uma dádiva concedida e singularizada a seus beneficiários. Mas isso parece levar a certa banalização da posse desse dinheiro, que passa a ser experimentada circunstancialmente (Werneck, 2019a), isto é, de modo "aberto para um perene estado de contingência e surpresa, na medida das circunstâncias que vão se impondo ad hoc, coordenando-se com os outros de forma também concebidas para o momento" (Werneck, 2020: 348). Os rendimentos do crime costumam ser direcionados a objetos de valor imediato, como "o carro do ano, uma moto maneira, uma roupa, um sapato maneiro" ou, ainda, "mulherada, curtir um show, ir pra festa, noitada, balada, beber as melhores bebidas...". Como descreveu um entrevistado, após o roubo de um carro ou uma moto, pensava: "Caramba, hoje estou aqui com R\$10 mil, R\$ 20 mil, posso ir ali gastar tudo no shopping. [...] Por um momento você se ilude, tu vê dinheiro que rende dinheiro, mas depois... Só Jesus".

Ao considerar que a ampla maioria dos engajados no mundo do crime é oriunda da classe de baixa renda, com pouco poder aquisitivo de partida, o poder (e a liberda- 
de) de compra proporcionados pelas atividades ilegais permite redescobrir o valor do dinheiro e de si próprios (Porto, 2019) mediante a posse de bens valorizados e reconhecidos. Contudo, em suas falas, o caráter ilusório atribuído no período de egressão ao mundo do crime é transmitido aos demais elementos dele provenientes: os amigos (reinterpretados como "falsos"), o dinheiro (ressignificado como "sujo"), o status aparentemente conquistado e mesmo o valor que se acreditava ter. Como diz um:

\begin{abstract}
Essa rua aí [o mundo do crime] é sem saída... É com saída enquanto tu tá aí na fama, tá no auge, tá indo para o baile, gastando mil, dois mil, tu tá rodeado de amigos. Mas quando a casa cai, amigo, sabe como é: ninguém pega uma guimba de cigarro e manda pra te fortalecer. Quando a casa cai, te tira tudo, tira família, amigos, tira tudo. Aí, quando tu foi ver, tu tá dentro do buraco sozinho. [...] Tu acha que tá no poder, que tá na fama, mas é tudo ilusão, cara.
\end{abstract}

Por sua vez, os titulares avaliativos dos processos também se digladiam com a representação do dinheiro como algo "fácil" em suas avaliações de danos morais: as indenizações, conquanto não possam ser "muito baixas", não podem tampouco implicar "enriquecimento ilícito" do indenizado - imperativo expresso no princípio da razoabilidade da avaliação (Sanseverino, 2010). Os magistrados costumam protocolarmente trazer em suas decisões sobre danos morais a observação da necessidade de observância desse princípio, a fim de justificar uma espécie de limite para as indenizações. Como diz um deles: "Não pode ser nem um valor alto, que desrespeite o princípio da razoabilidade, nem um valor tão baixo que não queira dizer nada, o que é aviltante, vitimiza a parte, os parentes da vítima, pela segunda vez".

Há, então, para os julgadores entrevistados, um "piso imaginário de decência" (o termo é de um ministro) e um teto imaginário de contenção. Não cabe à Justiça intervir na trajetória econômica dos indenizados, tornando-os ricos (se eles não forem). Por maiores que sejam suas perdas abstratas, elas nunca podem ser mobilizadas como substitutos da biografia como história da posse de dinheiro. A indenização tem que se explicitar destacadamente como compensação e não como acumulação. Um desembargador, responsável pela reforma de um julgamento, reduzindo um montante de danos morais da ordem de centenas de milhares de reais para $\mathrm{R} \$$ 25 mil, explica: "Não é um prêmio da loteria, que chega para mudar as vidas dos indenizados. As vidas deles já foram mudadas pela perda [no caso analisado, da honra]. É um curativo, que chega para tratar suas feridas". Por sua vez, um desembargador, ao analisar um caso em que o tribunal optou por reduzir a indenização "em uma casa" (de $\mathrm{R} \$ 100$ mil para $\mathrm{R} \$ 80$ mil), indica uma leitura simbólica do dinheiro: 
"É preciso levar em conta os ganhos atuais do indenizado, porque se a indenização for tão alta que o enriqueça ilicitamente, passa-se uma mensagem errada, esse dinheiro passa a ser um ganho desmerecido, que ele não fez por merecer. Nesse caso, parecia demais passar a casa dos 100 mil, poderia passar uma mensagem errada." Há também, dessa forma, uma construção de um self imaginado - virtual, nos termos de Goffman (1986), passível de ser efetivado ou não - em relação ao indenizando: ele é idealizado para ser modesto e contido, alguém que permanecerá sofrendo apesar da indenização, que não poderá receber a reparação como um bem hedonista e sim como um bem medicamentoso: ela deve combater a dor, não proporcionar prazer. Trata-se de um dinheiro "sério". Assim, hostiliza-se qualquer possibilidade de invasão da singularidade do sofrimento por uma dimensão econômica que a encapsule (algo expressado pelo termo "enriquecimento ilícito"). Nesse movimento, o self virtual do vitimado também é imaginado: ele é a vítima, alguém para quem o dinheiro se mostra em sua dimensão mais idealizada, como equivalente universal e metonímia da liberdade agencial): o equacionamento é entre a singularidade desse self vitimado e o caráter significativo de uma indenização que tenta ao mesmo tempo expressar a empatia (Clark, 2007) da Justiça com seu sofrimento e a vontade de devolver à vítima sua agência com ele perdida.

\section{O dinheiro "suado", a indenização "compensatória e razoável"}

Quando o dinheiro ganho expressa claramente uma fórmula de investimento ou a grandeza por ele expressa se coloca no lugar conveniente de uma forma de justiça (Boltanski \& Thévenot, 2020), ele é tomado como um "bom dinheiro" e, ao mesmo tempo, uma metonímia da grandeza adequada da existência em questão: ela se ergue da comprovação valorizada por uma quantia ou uma posse que, em caso de hostilização, poderia ser tratada como estigma, mas que aqui se mostra como presença harmônica da economia nas vidas das pessoas.

A renda proveniente do trabalho formal no período de egressão do sistema penitenciário costuma ser descrita como fonte geradora de rendimentos duráveis e observáveis ao longo do tempo, uma vez que é investida naquilo que "realmente importa", como descrevem os egressantes. Essa expressão, muito presente nas falas dos entrevistados, concerne àquilo a que dizem ter aprendido a "dar valor" no cárcere, normalmente se referindo ao âmbito da vida doméstica. Nesse quadro, um investimento naquilo que "realmente importa" corresponde às despesas que envolvem a casa e a dinâmica familiar. Na medida em que o dinheiro suado é fruto de um emprego mantido por exigência do benefício penal conquistado, esse montante agencia uma forma 
de liberdade outra, não a do poder de compra, mas a de um sentido mais literal do termo: manter-se fora das grades e cada vez mais distante dessa biografia.

Nesse caso, o dinheiro é empreendido com vistas a projetos de vida, ao futuro e ao compromisso de engajamento em um plano (Thévenot, 2006) e em mundos significativamente distintos daquele descrito anteriormente, os quais correspondem, no modelo da economia das grandezas (Boltanski \& Thévenot, 2020), aos mundos cívico (ele agora se integra a um todo como pequeno sob proteção de um Estado garantidor e ocupante da condição de grande), mercantil (ele agora trabalha e ganha seu dinheiro justo em troca de seu esforço) e do renome (ele reconstitui uma reputação e demonstra ajuste à dinâmica da opinião). Assim, o dinheiro pode ser tomado como objeto cuja instrumentalização se apresenta de maneiras distintas em cada um desses universos. Enquanto o dinheiro fácil "vai fácil", o dinheiro suado "é difícil se acabar", como descrevem os egressantes. O que fica em evidência nessa dicotomia é a percepção de um caráter efêmero sobre o primeiro, representado sob o aspecto ilusório do mundo que lhe é afim, em contraposição ao aspecto verdadeiro, legítimo e "real" atribuído não somente ao dinheiro suado, mas ao contexto no qual é produzido e conquistado. De fato, não se trata de o dinheiro oriundo do crime ser menos real, mas de haver uma fórmula de investimento (Boltanski \& Thévenot, 2020), um cálculo entre um sacrifício que paga "de verdade" e uma de relativa facilidade que paga, no final das contas, mal. Se, no mundo do crime, se gasta muito (porque se ganha muito) com bebidas, festas, roupas - isto é, com coisas que "passam", futilidades com as quais se pode gastar quando se tem "sobrando" -, no período de egressão do sistema, o dinheiro é contido e investido em coisas de retorno "mais definitivo", como as despesas da casa e da família - isto é, coisas que "duram" e cujo valor se pode ver "sempre". Nesse quadro, os rendimentos do "trabalho honesto" permitem ao egressante redescobrir um valor do dinheiro e de si próprio diretamente relacionado ao resgate de sua cidadania e à expectativa de manter a decisão anunciada pela ressaca.

Como disse um:

Aprendi na pele mesmo, sofri. Basta agora dar continuidade à minha vida, do lado certo. Porque não vale a pena, não. Prefiro ganhar pouco, ganhar menos, e não passar por isso de novo. Nem que eu coma arroz, feijão e ovo, mas eu vou comer na rua, que é completamente diferente de uma cadeia. É isso que eu espero pra mim. [...] Coisa que me leva pra cadeia eu quero distância. Eu prefiro tá no meu emprego, do lado da minha filha, da minha esposa, do meu pai, da minha mãe, da minha avó, do que tá no meio de várias amizades que possam me levar de novo para o mau caminho. 
No caso dos danos morais, o bom dinheiro é aquele que qualifica adequadamente a vítima como sofredora e o indenizando como injustiçado, pronunciando, como dissemos na seção anterior, o caráter modesto deste e o self decaído em grandeza daquele. Esse montante bom e sua boa posse costumam ter esse caráter positivo expresso por seu destino: ele serve, em um nível, para significar uma resposta em termos de justiça; em outro, ele é especulado a serviço de fins úteis, para pagar um psicólogo - muito embora esse tipo de despesa possa ser alocado nas indenizações por danos pessoais, muitos magistrados mobilizam essa possível despesa em suas justificativas -, para se fazer um curso e conseguir uma nova profissão uma vez que não seja mais possível atuar na anterior (por, por exemplo, se perder um membro ou se ficar traumatizado), para se fazer uma viagem e se recuperar da dor - algo sugerido por alguns magistrados, especialmente nos casos de pais que perdem fiIhos - ou, simplesmente, para se "refazer a vida":

Se esse dinheiro puder servir como base para as pessoas se refazerem do dano, ele terá desempenhado seu papel. É um gesto de fazer justiça com a paz de espírito das pessoas e com a sensação de que, afinal, a Justiça olhou por elas em uma hora em que sua identidade de humano foi agredida. As pessoas precisam poder se sentir pessoas de novo depois de um trauma e é para isso que serve uma indenização de danos morais.

As prestações de conta (Scott \& Lyman, 2008) a respeito do bom dinheiro dos danos morais, assim, se direcionam para seu bom uso pelos destinatários. Mas esse bom uso não é deixado ao sabor das agências: ele será previamente controlado pela temperança do juiz em Ihe oferecer o suficiente - e não mais que isso - para esse bom uso. Esse controle, dessa maneira, se torna o dispositivo privilegiado de comprovação da valorização da grandeza do indenizando porque a Justiça garantiria a manifestação de um self modesto pela oferta de uma indenização ela também contida. 


\section{Conclusões}

\begin{tabular}{|c|c|c|c|}
\hline & \multicolumn{2}{|c|}{ Egressante } & \multirow{2}{*}{ Juiz/Indenizando } \\
\hline & Criminoso & Trabalhador & \\
\hline $\begin{array}{l}\text { Forma do bem } \\
\text { representada pelo dinheiro }\end{array}$ & $\begin{array}{c}\text { Prazer } \\
\text { Distinção }\end{array}$ & $\begin{array}{l}\text { Sustento } \\
\text { Garantia de liberdade }\end{array}$ & $\begin{array}{l}\text { Compensação } \\
\text { "Reparação integral" }\end{array}$ \\
\hline $\begin{array}{l}\text { Forma actancial da } \\
\text { experiência com o dinheiro }\end{array}$ & $\begin{array}{c}\text { Fácil } \\
\text { Abundante }\end{array}$ & $\begin{array}{l}\text { Difícil } \\
\text { Escasso }\end{array}$ & $\begin{array}{c}\text { Ponderado } \\
\text { Parcialmente escasso }\end{array}$ \\
\hline Dinheiro errado & O do trabalho & O do crime & O do cálculo não razoável \\
\hline $\begin{array}{l}\text { Motivo da negatividade do } \\
\text { dinheiro }\end{array}$ & $\begin{array}{l}\text { "Mané" } \\
\text { Não compensa o sacrifício (de } \\
\text { trabalhar) porque paga pouco }\end{array}$ & $\begin{array}{l}\text { "Fácil" } \\
\text { Não compensa o sacrifício (de assu- } \\
\text { mir os riscos), porque é “ilusório" }\end{array}$ & $\begin{array}{l}\text { Enriquecimento ilícito (demais) } \\
\text { Não compensação integral (de menos) }\end{array}$ \\
\hline $\begin{array}{l}\text { Forma de sacrifício } \\
\text { (investimento condutor ao } \\
\text { dinheiro) }\end{array}$ & Risco da vida e da liberdade & $\begin{array}{c}\text { "Suor" } \\
\text { Modéstia } \\
\text { Postergação do gozo }\end{array}$ & $\begin{array}{l}\text { A perda originadora da ação (vítimas) } \\
\text { A contenção no uso dos recursos } \\
\text { (indenizandos) }\end{array}$ \\
\hline $\begin{array}{l}\text { Forma pedagógica do } \\
\text { dinheiro }\end{array}$ & $\begin{array}{l}\text { Catalisador do engajamento na vida } \\
\text { do crime }\end{array}$ & $\begin{array}{l}\text { Índice do cumprimento do benefício } \\
\text { penal concedido }\end{array}$ & $\begin{array}{l}\text { Dispositivo de punição exemplar } \\
\text { (judicial) } \\
\text { Dispositivo de ensinamento } \\
\text { existencial }\end{array}$ \\
\hline $\begin{array}{l}\text { "Lição" ensinada pelo } \\
\text { dinheiro }\end{array}$ & O crime compensa & A liberdade não tem preço & $\begin{array}{l}\text { A vida é preciosa e não pode ser } \\
\text { desvalorizada } \\
\text { A vida pode ser "refeita" }\end{array}$ \\
\hline Processo pedagógico & $\begin{array}{l}\text { Valorização de si mediante a posse } \\
\text { de bens até então inacessíveis }\end{array}$ & $\begin{array}{l}\text { Valorização de si mediante a } \\
\text { reconquista e a manutenção da } \\
\text { liberdade }\end{array}$ & $\begin{array}{l}\text { Informar ao réu que a vida tem valor e } \\
\text { não pode ser negligenciada como foi } \\
\text { (valorização das vidas singulares) } \\
\text { Informar ao indenizando que a Justiça } \\
\text { olhou por ele e que sua vida pode } \\
\text { seguir em frente }\end{array}$ \\
\hline $\begin{array}{l}\text { Dimensões significativas } \\
\text { (singularização do } \\
\text { recebedor) }\end{array}$ & $\begin{array}{c}\text { A abundância } \\
\text { A agência (do montante desmedido) }\end{array}$ & $\begin{array}{l}\text { A origem } \\
\text { O destino }\end{array}$ & $\begin{array}{l}\text { O montante (grandeza) razoável e } \\
\text { dotado de um fim modesto e portanto } \\
\text { justo }\end{array}$ \\
\hline Termos da significância & Graça, ganho inesperado & Ressaca & $\begin{array}{c}\text { Aquele caso singular e que se } \\
\text { distingue por humanos significativos }\end{array}$ \\
\hline
\end{tabular}

Elaboração própria

Esse quadro sintetiza o diálogo cruzado e simetrizador aqui esboçado, a explicitar sobretudo a maneira como os atores mobilizam o dinheiro como dispositivo de valorização das existências, isto é, das humanidades tomadas em seu estatuto de objeto de valor diante de sua finitude. Isso permitiu compreender como o econômico pode participar de um processo muitas vezes marcado pela hostilização da dimensão econômica - porque esta não representaria para os atores o que é sagrado (Abercrombie, 2020). E permitiu ainda mapear os processos por meio dos quais os dinheiros são definidos como bons ou maus em nossos campos e como isso pode ser extrapolado para a positivação do dinheiro como componente da valorização das existências em geral. 
Os pares dinheiro fácil/enriquecimento indevido e dinheiro suado/indenização justa são uma expressão da complexa coordenação entre hostilização e rotinização do econômico proporcionada pela sublimação do dinheiro como metonímia da valorização da existência. Enquanto o egressante qualifica qualitativamente uma monta quantitativa (o dinheiro tem mais importância do que a própria importância), os juízes quantificam uma perda qualitativa (afetos muitas vezes qualificados como o que "não se mede" ou "não tem preço"). O fato de os atores qualificarem uma versão positiva e uma negativa do dinheiro ao mesmo tempo, qualificando-o como bem moral e o integrando a um processo pedagógico, permite que ele compareça como actante central na valorização que torna significativa a existência humana ao se tornar ele próprio significativo.

Observamos aqui um caso específico, do que em outros trabalhos (Werneck, 2019b; Werneck et al. 2020), chamamos de disputas de valoração (isto é, aquelas relativas à definição dos quadros de valores atinentes às situações), aquele em que a dimensão conflitiva entre a dimensão econômica e outras dimensões consideradas pelos atores como não econômicas serve apenas como ponto de partida explicitador de uma solução ao fim e ao cabo coordenada com o econômico. Esses casos acabam por definir, por meio de suas operações de instauração, o estabelecimento, em uma parcela do empreendimento (aquela relativa a se sublinhar a sacralidade da existência) do que David Stark (2009) chamou de dissonâncias, friç̧ões produtivas entre quadros de valores, capazes, portanto, de definir as situações sem a necessidade de depuração valorativa e, mais ainda, beneficiando-se justamente da tensão entre os dois. Em outra parcela desse processo, entretanto, pareceu entrar em jogo aquilo que um de nós em outros textos (Werneck, 2019b; 2020) chamou de indefinição da situação, o fenômeno segundo o qual "os atores podem se beneficiar [...] de uma evitação/postergação [da] definição [da situação, nos moldes de Thomas], estabelecendo com o mundo indefinido uma fricção produtiva" (Werneck, 2020: 348): diante da pergunta de se o que está em jogo é uma prática existencial ou financeira, os atores parecem optar por, em vez de decidir, driblar a definição e deixar o mundo com esta resposta em suspenso, tirando partido de parcelas de um lado e de outro, enquanto possível.

No caso dos apontamentos de valores financeiros para expressar elementos abstratos ou intangíveis como a compensação pela perda de uma vida ou da capacidade de trabalho expressada pela perda de membros superiores ou a validade de um momento de sua biografia (como a "vida honesta" de um egressante do sistema prisional ou a vida no crime anteriormente experimentada), muitas vezes a condição de indefinição ou de dificuldade de definição do que seja econômico ou não oferece aos atores sociais todo um leque de possibilidade de ação da qual se bene- 
ficiam. Isso nos levou a pensar em como essas operações expressam um conjunto peculiar de formas denominadas por Thévenot (2006) engajamento, isto é, perguntando-nos sob que lógicas os atores se coordenam uns com os outros por meio de elementos integrantes das situações - neste caso, o dinheiro. E esse dinheiro se mostrou um elemento fundamental de percepção de um plano: ele traz à tona o fato de que a existência ali em jogo participa de um projeto com os elementos típicos do planejamento:

$[O]$ engajamento no plano é favorável à comunicação verbal como elemento da coordenação [...]. A cristalização em um plano se presta à exteriorização e à formação de depósitos capazes de oferecer meios de coordenação (Thévenot, 2006: 119).

Esse tipo de engajamento é percebido, segundo o autor, quando, na definição da situação, é possível designar determinados elementos-chave um planejador, um objetivo e elementos (dispositivos) capazes de orientar a situação no sentido dessa meta. Assim, em nossas pesquisas, o dinheiro se mostrou um especial dispositivo capaz de oferecer a relação entre, de um lado, a biografia ou o valor intrínseco da vida e, de outro, o projeto de sua valorização. É ele que oferece a comprovação (Boltanski \& Thévenot, 2020), o momento de avaliação sobre o valor da existência, justamente ao ingressar como personagem na situação em que aquelas vidas humanas entram em jogo. Nesse quadro, o planejador se torna indicial: de um lado, a biografia explicita um domínio sobre o próprio plano, atribuindo ao indivíduo essa posição actancial; de outro, o reconhecimento do valor da vida atribui ao avaliador externo esse lugar. Em ambos os casos, a planificação se torna a maneira de qualificar a existência: ela se integra como um todo coerente em um horizonte temporal - nos casos específicos de nossos campos, seja como carreira seja como processo judicial, mas no sentido mais amplo, como projeção de uma existência em uma história dotada de sentido.

A simetrização analítica de nossas pesquisas de campo, conquanto tenham permitido enxergar as formas peculiares como em cada um deles a valorização de uma existência é operada, permitiu observar o comum entre ambos, na ordem dos regimes de valorização explicitados por cada um (e em funcionamento em ambos). As maneiras como o dinheiro é tratado como um bem (em sua articulação com a humanidade); como ele se torna um actante nessas comprovações; como ele é qualificado como bom ou mau (certo ou errado); como ele qualifica uma fórmula de investimento (um sacrifício) para o humano em questão; como ele assume uma forma pedagógica, implicando um processo pedagógico e ensinando uma lição específica; e a forma como ao fim qualifica uma existência significativa. Tudo isso compõe uma matriz de elementos gramaticais definidores dos dois regimes 
de valorização da existência aqui explicitados: o biográfico e o de reconhecimento intrínseco. Essas duas formas de tornar existências (isto é, humanidades refletidas) algo significativo e, portanto, valorizável, são intermediadas justamente pela relação com o dinheiro, algo tornado possível por uma indefinição que permite ao dinheiro ser e não ser uma tradução do econômico e do existencial, permitindo aos atores sociais se beneficiarem da dissonância entre existência e economia.

\section{Referências}

ABERCROMBIE, Nicholas. Commodification and its discontents. London: Polity, 2020.

ASH, William. Marxismo e moral. Rio de Janeiro: Zahar, 1965.

BAIER, Kurt. The concept of value. In: LASZLO, Ervin; WILBUR, James B. Value theory in philosophy and social science, p. 1-11. London: Routledge, 1973.

BARBOSA, Antônio Rafael. O baile e a prisão: onde se juntam as pontas dos segmentos locais que respondem pela dinâmica do tráfico de drogas no Rio de Janeiro. Cadernos de Ciências Humanas: Especiaria, v. 9, n. 15, p. 119-135, 2006.

BITTAR, Carlos Alberto. Reparação civil por danos morais. São Paulo: Saraiva, 2015.

BLOCH, Maurice; PARRY, Jonathan. Money and the morality of exchange. Cambridge, UK: Cambride University Press, 1989.

BOLTANSKI, LUC; THÉVENOT, Laurent. A justificação: sobre as economias da grandeza. Rio de Janeiro: Editora UFRJ, 2020 [1991].

BROSCH, Tobias; SANDER, David. From values to valuaton: an interdisciplinar approach to the study of values. In: Handbook of value, p. 397-404. London: Oxford University Press, 2016.

CALLON, Michel; LATOUR, Bruno. Don't throw the baby out with the bath school! A reply to Collins and Yearly. In: PICKERING, Andrew (Org.). Science as practice and culture, p. 343-368. Chicago, IL: University of Chicago Press, 1992.

CEFAÏ, Daniel; ZIMMERMANN, Bénédicte; NICOLAE, Stefan; ENDREß, Martin. Introduction: sociology of valuation and evaluation. Human Studies, v. 38, n. 1, p. 1-12, 2015

CICOUREL, Aaron V. Method and measurement in sociology. New York: The Free Press, 1964. 
CLARK, Candace. Misery and company: sympathy in everyday life. Chicago, IL: University of Chicago Press, 2007.

COOLEY, Charles Horton. Human nature and the social order. New York: Charles Scribner's Sons, 1902.

DE LASTIC, Adélaïde. Que valent les valeurs? Paris: L'Harmatan, 2014.

DEWEY, John. Logic: the theory of inquiry. New York: Henry Holt, 1938.

FELTRAN, Gabriel de Santis. O valor dos pobres: a aposta no dinheiro como mediação para o conflito social contemporâneo. Caderno CRH, v. 27, n. 72, p. 495-512, 2014.

. O legítimo em disputa: as fronteiras do "mundo do crime" nas periferias de São Paulo. Dilemas: Revista de Estudos de Conflito e Controle Social, v. 1, n. 1, p. 93-126, 2008.

FREIRE, Jussara. Agir no regime de desumanização: esboço de um modelo para análise da sociabilidade urbana na cidade do Rio de Janeiro. Dilemas: Revista de Estudos de Conflito e Controle Social, v. 3, n. 4, p. 119-142, 2010.

FREIRE, Jussara; TEIXEIRA, César Pinheiro. Humanidade disputada: Sobre as (des) qualificações dos seres no contexto de "violência urbana" do Rio de Janeiro. Terceiro Milênio: Revista Crítica de Sociologia e Política, v. 6, n. 1, p. 58-85, 2016.

GOFFMAN, Erving. Stigma: notes on the management of spoiled identity. New York: Touchstone, 1986 [1963].

Manicômios, prisões e conventos. São Paulo, Perspectiva, 1974 [1961].

GRAEBER, David. Toward an anthropological theory of value: the false coin of our own dreams. New York: Palgrave, 2001.

GREIMAS, Algirdas J. Semântica estrutural: pesquisa de método. São Paulo: Cultrix; Editora da USP, 1976 [1966].

GRILLO, Carolina. Coisas da vida no crime: tráfico e roubo em favelas cariocas. Tese (Doutorado) - Programa de Pós-Graduação em Sociologia e Antropologia (PPGSA) da Universidade Federal do Rio de Janeiro (UFRJ), Rio de Janeiro, RJ, 2013.

HEILBRONER, Robert L. The problem of value in the construction of economic thought. Social Research, v. 50, n. 2, p. 253-277, 1983. 
HEINICH, Nathalie. Des valeurs: une approche sociologique. Paris: Gallimard, 2017. HIRATA, Daniel Veloso. Sobreviver na adversidade: entre o mercado e a vida. Tese (Doutorado em Sociologia) - Faculdade de Filosofia, Letras e Ciências Humanas (FFLCH) da Universidade de São Paulo (USP), São Paulo, SP, 2010.

HONNETH, Axel. Luta por reconhecimento: a gramática moral dos conflitos sociais. São Paulo: Editora 34, 2009 [1992].

JAMES, William. The principles of psychology. Oxford, UK: Dover, 1950 [1890]. Pragmatism: A new name for some old ways of thinking. Cambridge, MA: Harvard University Press, 1907.

KARPIK, Lucien. Valuing the unique: the economics of singularities. Princeton, NJ: Princeton University Press, 2010.

KLUCKHOHN, Clyde. Values and value-orientations in the theory of action: an exploration in definition and classification. In: PARSONS, Talcot; SHILS, Edward (Orgs.). Toward a general theory of action, p. 388-433. Cambridge, MA: Harvard University Press, 1951.

LATOUR, Bruno. Ciência em ação: como seguir cientistas e engenheiros sociedade afora. São Paulo: Editora Unesp, 1997 [1987].

LYRA, Diogo. A república dos meninos: juventude, tráfico e virtude. Rio de Janeiro: Mauad, 2013.

MACHADO DA SILVA, Luiz Antônio. Violência urbana: representação de uma ordem social. In: NASCIMENTO, Elimar Pinheiro; BARREIRA, Irlys (Orgs.). Brasil urbano: cenário da ordem e da desordem, p. 131-142. Rio de Janeiro, Notrya, 1993.

MACHADO DA SILVA, Luiz Antônio; LEITE, Márcia. Violência, crime e polícia: o que favelados dizem quando falam desses temas?". In: MACHADO DA SILVA, Luiz Antonio (Org.). Vida sob cerco: violência e rotina nas favelas do Rio de Janeiro, p. 47-76. Rio de Janeiro: Faperj; Nova Fronteira, 2008.

MEAD, George Herbert. Mind, self, and society: from the standpoint of a social behaviorist. Chicago, IL: University of Chicago Press, 1934.

MISSE, Michel. Malandros, marginais e vagabundos: a acumulação social da violência no Rio de Janeiro. Tese (Doutorado) - Instituto Universitário de Pesquisas do Rio de Janeiro (Iuperj), Universidade Cândido Mendes, Rio de Janeiro, RJ, 1999. 
MUNHOZ, Sara Regina. Confiscações semânticas e afetivas: famílias na jurisprudência do Superior Tribunal de Justiça. In: VILLELA, Jorge Mattar; ALENCAR VIEIRA, Suzane de (Orgs.). Insurgências, ecologias dissidentes e antropologia modal, p. 210243. Goiânia: Imprensa Universitária, 2020.

NEIBURG, Federico. Os sentidos sociais da economia. In: DIAS DUARTE, Luiz Fernando (Org.). Horizontes das ciências sociais no Brasil: antropologia. São Paulo: Anpocs; Barcarolla; Discurso Editorial, 2010.

PEDERSEN, David. Introducton: toward a value theory of anthropology. Anthropological Theory, v. 8, n. 1, p. 5-8, 2008.

PEIRCE, Charles S. How to make our ideas clear. In: The essential Peirce, v. 1: "Selected philosophical writings (1867-1893)", p. 124-141. Bloomington, IN: Indiana University Press, 1992 [1878].

. Divisão dos signos. In: Semiótica, p. 45-61. São Paulo, Perspectiva, 1977 [1897].

PORTO, Camille. Selves em cadeia: um estudo sociológico sobre a carreira moral de "egressantes" do sistema penitenciário fluminense. Dissertação (mestrado) - Programa de Pós-Graduação em Sociologia e Antropologia (PPGSA), Universidade Federal do Rio de Janeiro (UFRJ), 2017.

O que há de moral na carreira moral: sobre dispositivos de transformação de si em "egressantes" do sistema penitenciário. Dilemas: Revista de Estudos de Conflito e Controle Social, v. 12, n. 3, p. 477-498, 2019.

RAMALHO, José Ricardo. Mundo do crime: a ordem pelo avesso. Rio de Janeiro, Graal, 1979.

REZSOHAZY, Rudolf. Sociologie des valeurs. Paris: Armand Colin, 2006.

SCOTT, Marvin B.; LYMAN, Stanford M. Accounts. Dilemas: Revista de Estudos de Conflito e Controle Social, v. 1, n. 2, p. 139-172, 2008 [1968].

SANSEVERINO, Paulo de Tarso Vieira. Princípio da reparação integral: indenização no CódigoCivil. São Paulo: Saraiva, 2010.

SIMMEL, Georg. The philosophy of money. London: Routledge, 2011 [1908].

STARK, David. The sense of dissonance: accounts of worth in economic life. Princeton, NJ: Princeton University Press, 2009. 
TEIXEIRA, César Pinheiro. A teia do bandido: um estudo sociológico sobre bandidos, policiais, evangélicos e agentes sociais. Tese (Doutorado), Programa de Pós-Graduação em Sociologia e Antropologia (PPGSA)da Universidade Federal do Rio de Janeiro (UFRJ), Rio de Janeiro, RJ, 2013.

THÉVENOT, Laurent. L'action au pluriel: sociologies des régimes d'engagement. Paris: La Découverte, 2006.

THOMAS, William I. The unadjusted girl: with cases and standpoint for behaviour analysis. Monclair, CA: Patterson Smith, 1969 [1923].

THOMAS, William I.; THOMAS, Dorothy Swaine. The child in America: behavior problems and programs. New York: A. A. Knopf, 1938 [1928].

WEBER, Florence. Práticas econômicas e formas ordinárias de cálculo. Mana: Estudos de Antropologia Social, v. 8, n. 2, p. 151-182, 2002.

WEBER, Max. The theory of social and economic organization. Glencoe, UK: The Free Press, 1947 [1922].

WERNECK, Alexandre. Apontamentos para uma sociologia da efetivação (isto é, uma sociologia pragmática). In: NEVES, Fabrício; CORRÊA, Diogo; PETERS, Gabriel (Orgs.). Construção conceitual nas ciências sociais. Petrópolis, RJ: Vozes, 2021 (no prelo).

Obstáculos na "pista livre": algumas considerações sobre a pragmática dos dispositivos da "lei do trânsito" no Rio de Janeiro. Antropolítica: Revista Contemporânea de Antropologia, n. 50, p. 327-355, 2020.

O milagre da multiplicação: valores, situações e circunstâncias. Sobre "A lenda do santo beberrão", de Joseph Roth. Trabalho apresentado no seminário Ficção e Ciências Sociais, IFCS, UFRJ, 2019a.

A moral dos danos, o valor da moral: avaliações de indenizações como formas de valorização significativa. Trabalho elaborado para apresentação no I Seminário Internacional Questões de Moral, Moral em Questão: Sociologia e Antropologia do Bem em Tempos Desafiadores, postergado para 2021 por conta da pandemia, IFCS, UFRJ, 2019b.

Dar uma zoada, botar a maior marra: dispositivos morais de jocosidade como formas de efetivação e sua relação com a crítica. Dados: Revista de Ciências Sociais, v. 58, n. 1, 2015, p. 187-222. 
Sociologia da moral, agência social e criatividade. In: WERNECK, Alexandre; CARDOSO DE OLIVEIRA, Luís Roberto (Orgs.). Pensando bem: estudos de sociologia e antropologia da moral, p. 25-48. Rio de Janeiro: Casa da Palavra, 2014.

. A desculpa: as circunstâncias e a moral das relações sociais. Rio de Janeiro, Civilização Brasileira, 2012.

WERNECK, Alexandre; MOTTA, Eugenia; LORETTI, Pricila; CORRÊA, Diogo; SALES, Samantha; TALONE, Vittorio da Gama; PORTO, Camille. Conflitos de valoração: as disputas e a administração de diferentes sentidos dos "bjetos de valor" entre legal, ilegal, estado e cidadãos no Rio de Janeiro. Relatório de pesquisa, CNPq, 2020.

WERNECK, Alexandre; SALES, Samantha. A indefinição capital: Uma sociologia das definições de economia a partir das hostilizações ao econômico. Texto de trabalho, Necvu, 2020.

WILKIS, Ariel. Las sospechas del dinero: moral y economía en la vida popular. Buenos Aires: Paidós, 2013.

WILLIAMS, Christopher J. F. What is existence? Oxford, UK: Clarendon, 1982.

ZALUAR, Alba. Violência, dinheiro fácil e justiça no Brasil: 1980-1995. In: ACSELRAD, Gilberta (Org.). Avessos do prazer: drogas, Aids e direitos humanos, p. 65-88. Rio de Janeiro: Editora Fiocruz, 2005.

. Integração perversa: Pobreza e tráfico de drogas, v. 1. Rio de Janeiro: Editora FGV, 2004.

A máquina e a revolta. São Paulo: Brasiliense, 1985.

ZELIZER, Viviana A. A negociação da intimidade. Petrópolis, RJ: Vozes, 2011 [2005]. 